\title{
POLÍTICAS DE EDUCAÇÃO DO CAMPO NO TERRITÓRIO DE IDENTIDADE SERTÃO PRODUTIVO NA BAHIA-BRASIL: APONTAMENTOS DE PESQUISA
}

\author{
POLÍTICAS DE EDUCACIÓN DEL CAMPO EN EL TERRITORIO DE IDENTIDAD \\ SERTÃO PRODUCTIVO EN BAHIA-BRASIL: APUNTES DE INVESTIGACIÓN
}

\author{
POLICIES OF RURAL EDUCATION IN THE IDENTITY TERRITORY PRODUCTIVE \\ HINTERLAND IN BAHIA-BRAZIL: RESEARCH NOTES
}

\author{
Tatyanne Gomes MARQUES ${ }^{1}$ \\ Eugênia da Silva PEREIRA ${ }^{2}$ \\ Priscila Teixeira da SILVA ${ }^{3}$
}

RESUMO: Este texto tem por objetivo apresentar e analisar as políticas de Educação do Campo no microcontexto do Território de Identidade Sertão Produtivo na Bahia - Brasil. O estudo se situa no campo das políticas públicas educacionais e centra-se nas propostas implementadas e/ou reivindicadas por diferentes atores e atrizes que protagonizam a vida e atuam no microcontexto focalizado. Para isso, faz uso de uma metodologia de revisão bibliográfica das produções de 2009 a 2020 da linha de pesquisa "Educação do Campo, Educação de Jovens e Adultos e Movimentos Sociais", do Núcleo de Estudo, Pesquisa e Extensão Educacional Paulo Freire (NEPE), da Universidade do Estado da Bahia (UNEB), que tem o Sertão Produtivo como lócus principais de suas investigações. $\mathrm{O}$ levantamento das produções evidencia uma produção diversa - teses, dissertações, Trabalho de Conclusão de Curso, artigos em periódicos e anais de eventos. A análise dessas produções confirma, no cenário local, as contradições da política pública para a Educação do Campo: uma crescente visibilização dessa modalidade educacional e seus/suas protagonistas; a inserção dessa pauta nos marcos legais e nas políticas municipais, ao mesmo tempo que ocorre o fechamento e a nucleação extracampo das escolas, políticas de formação e trabalho docente universalistas, bem como práticas pedagógicas que, enquanto escolhas políticas, negam a identidade e cultura dos povos do campo.

PALAVRAS-CHAVE: Políticas públicas educacionais. Território de identidade sertão produtivo. Educação do campo.

${ }^{1}$ Universidade do Estado da Bahia (UNEB), Guanambi - BA - Brasil. Professora no Departamento de Educação - DEDC XII. Pesquisadora vinculada ao Núcleo de Estudo, Pesquisa e Extensão Educacional Paulo Freire (NEPE/UNEB) e ao Programa de Pós-Graduação em Educação (PPGED/UESB). Doutorado em Educação (UFMG). ORCID: https://orcid.org/0000-0003-3076-3220. E-mail: tmarques@uneb.br

${ }^{2}$ Universidade do Estado da Bahia (UNEB), Guanambi - BA - Brasil. Professora no Departamento de Educação - DEDC XII. Pesquisadora vinculada ao Núcleo de Estudo, Pesquisa e Extensão Educacional Paulo Freire (NEPE/UNEB). Mestrado Profissional em Educação do Campo (UFRB). ORCID: https://orcid.org/0000-00018867-9481. E-mail: eniagbi@hotmail.com

3 Universidade do Estado da Bahia (UNEB), Guanambi - BA - Brasil. Doutoranda no programa de pósGraduação em Educação e Contemporaneidade. Pesquisadora vinculada ao Núcleo de Estudo, Pesquisa e Extensão Educacional Paulo Freire (NEPE/UNEB). ORCID: https://orcid.org/0000-0001-5042-8767. E-mail: priscilats4@hotmail.com

RIAEE - Revista Ibero-Americana de Estudos em Educação, Araraquara, v. 16, n. esp. 2, p. 1267-1285, maio 2021. e-ISSN: 1982-5587 
RESUMEN: Este texto tiene por objeto presentar y analizar las politicas de Educación del Campo en el microcontexto del Territorio de Identidad Sertão Productivo en Bahía - Brasil. El estudio se ubica en el campo de las políticas educacionales y se centra en las propuestas implementadas y/o revindicadas por diferentes actores y actrices que protagonizan la vida $y$ actúan en el microcontexto enfocado. Para ello, se utiliza una metodología de revisión bibliográfica de las producciones de 2009 a 2020 de la línea de investigación "Educación del Campo, Educación de Jóvenes y Adultos y Movimientos Sociales”, del Núcleo de Estudio, Investigación y Extensión Educacional Paulo Freire (NEPE), de la Universidad del Estado de Bahía (Uneb), que tiene el Sertão Productivo como locus principal de sus investigaciones. La recopilación de las producciones evidencia una producción diversa - tesis, disertaciones, Trabajo de Conclusión de Curso, artículos en revistas científicas y anales de eventos. El análisis de esas producciones confirma, en el escenario local, las contradicciones de la política pública para la Educación del Campo: una creciente visibilidad de esa modalidad educacional y sus protagonistas; la inserción de esa pauta en los hitos legales y en las políticas municipales, al mismo tiempo que ocurre el cierre y la nucleación extra-campo de las escuelas, políticas de formación y trabajo docente universalistas, así como prácticas pedagógicas que, como escuelas políticas, niegan la identidad y cultura de los pueblos del campo.

PALABRAS CLAVE: Políticas públicas educacionales. Territorio de identidad sertão productivo. Educación del campo.

ABSTRACT: This text has for objective to present and to analyze the policies of Rural Education in the microcontext of the Territory of Identity Productive Hinterland in Bahia-Brazil. The study is located in the field of educational public policies and focuses on the proposals implemented and/or claimed by different actors and actresses who are protagonists of life and act in the focused micro context. For this, it uses a methodology of bibliographic review of the productions from 2009 to 2020 of the research line "Rural Education, Education of Youths and Adults and Social Movements", of the Center for Study, Research and Educational Extension Paulo Freire (NEPE), from the State University of Bahia (UNEB), which has the Productive Hinterland as the main locus of its investigations. The survey of the productions shows a diverse production theses, dissertations, Course Conclusion Work, articles in periodicals and annals of events. The analysis of these productions confirms, in the local scenario, the contradictions of the public policy for Rural Education: an increasing visibility of this educational modality and its protagonists; the insertion of this agenda in the legal frameworks and in the municipal policies, at the same time as the closure and the out-of-field nucleation of schools, universalist formation policies and teaching work, as well as pedagogical practices that, as political choices, deny the identity and culture of the people from the rural.

KEYWORDS: Educational public policies. Identity territory productive hinterland. Rural education.

\section{Introdução}

As pesquisas no campo da política educacional estudam as relações de força e disputa pela concretização da educação. Por assim se constituir, Oliveira (2010) ressalta que, embora as políticas públicas do Estado apresentem-se como dirigidas pelo interesse universal, devem ser 
compreendidas como resultantes de correlação de forças entre distintos projetos. É a partir dessa compreensão que analisamos neste texto as políticas de Educação do Campo em um contexto mais amplo e também no Território de Identidade Sertão Produtivo ${ }^{4}$.

A Educação do Campo tem em sua gênese um projeto de sociedade, campo e educação que se coloca em disputa com o projeto de sociedade, campo e educação do capital. Enquanto o capitalismo se configura no campo por meio do agronegócio e do minerionegócio, gerando aparência de progresso, o projeto popular da Educação do Campo se pauta em uma matriz para além do capital (FRIGOTTO, 2010; MÉSZÁROS, 2011; RIBEIRO, 2010). Portanto, como Santos, Barbosa e Rosset (2017, p. 17) afirmam, "a Educação do Campo se torna um projeto histórico para consolidar outro paradigma de campo" que se baseia "na identidade camponesa, na memória histórica da resistência e no conjunto de saberes que modelam os modos de ser, de estar e de viver no campo".

A Educação do Campo e, consequentemente, as políticas públicas de educação do campo vinculam a luta por educação ao conjunto de lutas pela transformação social das condições de vida no campo (CALDART, 2002). Nessa perspectiva, ao focalizamos aqui as políticas públicas de Educação do Campo no Território de Identidade Sertão Produtivo, Bahia, analisamos um conjunto de ações empreendidas nos microcontextos dos municípios para garantir e implementar as orientações dos marcos legais, os programas e as políticas de Educação do Campo conquistadas no cenário nacional.

Para a análise aqui proposta, tomamos como referência os dados de estudos desenvolvidos por um conjunto de pesquisadores/as que compõe o Núcleo de Estudo, Pesquisa e Extensão Educacional Paulo Freire (NEPE) do Departamento de Educação - DEDC XII - da Universidade do Estado da Bahia (Uneb). Os mencionados estudos foram desenvolvidos pela linha de pesquisa "Educação do Campo, Educação de Jovens e Adultos e Movimentos Sociais" ao longo de mais de 10 anos - 2009 a 2020. Tomamos como referência as pesquisas dessa linha porque compreendemos que são elas que têm focalizado as políticas de Educação do Campo no Território Sertão Produtivo, lócus da nossa análise.

Para acessar as pesquisas e as produções delas resultantes, fizemos o levantamento dos/as pesquisadores/as da referida linha e analisamos, a partir de seus currículos, as publicações que dão centralidade às políticas de Educação do Campo no Território de Identidade Sertão Produtivo Bahia, Brasil. Para isso, utilizamos os descritores "Educação do Campo", "Educação rural", "Políticas públicas educacionais", "Políticas públicas e educação do/no campo". A partir desse

${ }^{4}$ Referimo-nos a um microcontexto formado por vinte municípios na região sudoeste da Bahia, conforme apresentamos no item 2 .

RIAEE - Revista Ibero-Americana de Estudos em Educação, Araraquara, v. 16, n. esp. 2, p. 1267-1285, maio 2021. e-ISSN: 1982-5587 
levantamento, identificamos duzentos e setenta e cinco produções que tratam das políticas de Educação do Campo, sendo teses e dissertações dos/as pesquisadores/as; artigos completos publicados em anais de eventos; artigos publicados em periódicos; capítulos de livros; TCC de graduação e TCC de especialização Lato Sensu; e ainda pesquisas de Iniciação Científica.

Dessas publicações, cem focalizam o contexto do território analisado em uma perspectiva de análise da política educacional para a educação básica. Essas produções, ao serem objeto de análise, foram agrupadas e categorizadas em quatro eixos temáticos: políticas públicas de Educação do Campo e gestão; política de fechamento e nucleação das escolas na cidade; política de formação e trabalho de professores/as e, por fim, o eixo que trata das escolhas políticas e pedagógicas articuladas às práticas e identidades das escolas do campo no Sertão Produtivo.

Para melhor compreensão deste texto, inicialmente apresentamos os modelos de desenvolvimento em disputa nos territórios rurais e suas implicações para as políticas de Educação do Campo. Essa apresentação se faz necessária para compreensão do Território de Identidade Sertão Produtivo como microcontexto das pesquisas e também como parte das disputas de projetos da educação.

\section{Modelos de desenvolvimento - em disputa - nos territórios rurais: implicações para as políticas de Educação do Campo}

O Brasil tem historicamente uma organização agrária que demarca a divisão de duas perspectivas de desenvolvimento para o meio rural. Mesmo com proporções continentais, é um dos países com maior concentração de terras, um índice Gini $^{5}$ de 0,73 , segundo o estudo "Quem são os poucos donos das terras agrícolas no Brasil - O Mapa da Desigualdade”, publicado em 2020. Já de acordo dados do censo agropecuário de 2017, 41\% da área nacional é voltada para a agropecuária. As grandes propriedades detêm 47,5\% dessa área (IBGE, 2017).

Tal configuração evidencia o conflito de classes e de modelos de desenvolvimento presentes no meio rural. Um deles, fundamentado no latifúndio, no agronegócio, no campo como espaço apenas de produção econômica; e o outro da pequena propriedade, do campesinato, do campo como espaço de totalidade, de vida, onde as relações socioculturais demarcam um modo de viver e persistir.

Segundo Fernandes (2013), a análise de tal realidade vem sendo feita com base em disputas paradigmáticas: o paradigma da questão agrária e o paradigma do capitalismo agrário. Enquanto o capitalismo agrário corrobora com o fim do campesinato pelo avanço do capital no

5 O Coeficiente de Gini, criado para analisar a concentração de renda e depois utilizado para calcular a concentração de terras, consiste em um número entre 0 e 1 , em que 0 é igualdade total e 1 desigualdade total.

RIAEE - Revista Ibero-Americana de Estudos em Educação, Araraquara, v. 16, n. esp. 2, p. 1267-1285, maio 2021. e-ISSN: 1982-5587 
meio rural, representado pelo agronegócio, o paradigma da questão agrária "tem como ponto de partida as lutas de classes para explicar as disputas territoriais e suas conflitualidades na defesa de modelos de desenvolvimento que viabilizem a autonomia dos camponeses" (FERNANDES, 2013, p. 69).

Nessa dinâmica da relação de disputas territoriais, Fernandes (2015) afirma que o campesinato tem se organizado para defender um outro modelo de desenvolvimento fundamentado no campo como espaço de totalidade. E cita como exemplos de documentos que tem evidenciado isso "O Programa Agrário do Movimento dos Trabalhadores e Trabalhadoras em Terra (MST)" e o "Plano Camponês" do Movimento dos Pequenos Agricultores (MPA). Ambos definem os principais pontos ou diretrizes de um modelo de desenvolvimento.

O Programa Agrário do MST é orientado pela garantia da vida digna do povo do campo pelo acesso a terra, à soberania alimentar, à educação contra a exploração do trabalho, fundamentado na sustentabilidade. O Plano Camponês do MPA busca a definição da identidade conceitual como forma de demarcar espaço na política pública, as condições técnicas, financeiras e organizacionais para produção na perspectiva agroecológica e aspectos relacionados ao acesso de bens e serviços que garantam a qualidade de vida. A educação é um dos elementos em comum em ambas propostas e ausente no Paradigma do Capitalismo Agrário, já que neste o campo está fadado ao vazio populacional.

Destacamos essas perspectivas nesta análise porque são elas que têm orientado a definição de políticas públicas para a educação rural e do/no campo no país e no microcontexto a que nos referimos. Segundo Fernandes (2015, p. 382), “a elaboração de políticas públicas é resultado da correlação de forças entre instituições que são ou representam interesses de classes. São as partes interessadas que em suas proposições de políticas, defendem seus respectivos modelos de desenvolvimento". A complexidade de tal fato é visível ao se observar a concomitância de políticas divergentes em um mesmo governo e/ou momento histórico, a exemplo das últimas décadas, quando nasce o Movimento Por uma Educação do Campo e se conquistam marcos legais, programas e políticas, concomitantemente com os altos investimentos estatais no agronegócio, com o fechamento das escolas no campo e desmonte dessas recentes conquistas.

Tal disputa de projetos tem pendido recentemente para o capital, após golpe político ocorrido em 2016 e chegada ao poder do governo subsequente. Este tem reforçado ainda mais o apoio do Estado burguês ao capitalismo agrário.

Feitas essas considerações, ressaltamos que analisar as políticas públicas de educação é demarcar as disputas de interesses de projetos de desenvolvimento antagônicos que, segundo Fernandes (2015), a depender da correlação de forças, podem se caracterizar como políticas 
públicas de subordinação ou políticas públicas emancipatórias. O modo como o campo é visto acaba determinando que tipo de educação é ofertada para quem vive nele. Quando se acredita no despovoamento do campo, a educação forma para a cidade; caso se preconizem os modelos desenvolvimentistas vinculados ao capitalismo agrário, implanta-se a formação técnica atrelada ao modo de produção capitalista. Já quando o campo é reconhecido como espaço de vida, tende-se a fomentar uma educação vinculada às lutas e anseios dos povos do campo (SILVA, 2015). As duas primeiras perspectivas, atreladas à criação de políticas públicas de subordinação, forçam os povos do campo a se adaptarem à lógica de desenvolvimento e produção capitalista. Em contraponto, políticas públicas emancipatórias se fundamentam em uma lógica contra hegemônica.

É, portanto, a análise dessas antíteses que nos propomos a apresentar e compreender no contexto do Território de Identidade Sertão Produtivo. Nosso olhar se volta às políticas de Educação do Campo propostas, implementadas e/ou reivindicadas por diferentes atores e atrizes que protagonizam a vida e atuação nesse microcontexto.

\section{O Território de Identidade Sertão Produtivo - Bahia/Brasil: microcontexto das pesquisas}

O Ministério do Desenvolvimento Agrário (MDA), com a criação da Secretaria de Desenvolvimento Territorial (SDT), e da Coordenação Estadual de Territórios no estado da Bahia/Brasil, ao buscar o desenvolvimento em todas as regiões, instituíram a territorialidade como instrumento para o planejamento e para a tomada de decisões compartilhadas entre agentes da sociedade civil e do poder público. Na Bahia, atualmente existem vinte e sete Territórios de Identidade, sendo um deles denominado Sertão Produtivo.

O Território Sertão Produtivo é composto por 20 municípios e possui uma população de 460.794 habitantes (IBGE, 2010). 
Figura 1 - Mapa do Território Sertão Produtivo

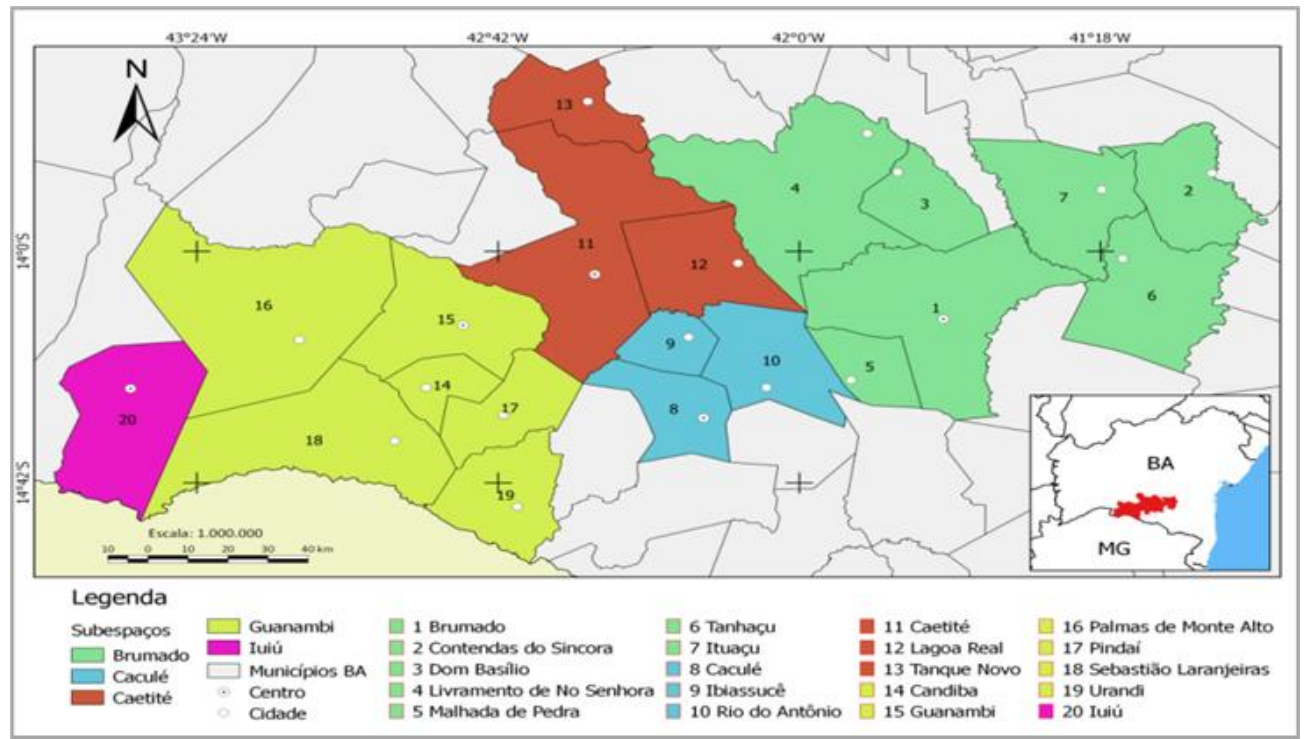

Fonte: Silva, Lima e Bebé (2016)

O Território Sertão Produtivo, por características da sua população e também socioeconômicas, foi definido como sendo um território rural. Esse é um contexto com uma alta taxa de população rural do território, já que são 210.174 habitantes, o que equivale a $45,6 \%$ do total (IBGE, 2010). Destaca-se que quinze dos vinte municípios do território têm um percentual de população rural superior à urbana.

De acordo com informações do Plano de Desenvolvimento Territorial do Sertão Produtivo - PDTSP (PDTSP, 2010), essa região, no período colonial, era ocupada por indígenas "tapuias" (os mais antigos do Brasil) e "tamoios". Posteriormente, na segunda metade do século XIX, por remanescentes de botocudos, pataxós, mongóis, imborés, camacãs, maracás. Muitos índios dessas etnias foram dizimados (as), outros expulsos ou absorvidos como mão de obra na agropecuária, perdendo a identidade étnico-cultural após a interiorização das fazendas de gado no Vale do Rio São Francisco, devido ao avanço das lavouras de cacau e cana de açúcar no litoral, e da exploração de ouro e diamantes por decorrência do sistema de sesmarias.

Foi também devido à mineração que se formaram os primeiros povoados. A mineração é ainda na atualidade um forte determinante econômico do território, pois é nessa região que se encontra a maior concentração de minérios do estado da Bahia.

Além da forte presença das grandes fazendas de algodão, criação de gado e da extração de minérios em todo o território, em 2012 foi inaugurado o maior complexo eólico da América Latina nos municípios de Caetité, Guanambi e Igaporã, sob o comando da empresa Renova Energia (SILVA, 2015). 
A configuração desse território tem como característica a desigualdade nos aspectos econômico, político, cultural e social, onde a supremacia dos grandes fazendeiros e, na atualidade, de grandes empreendimentos, se contrapõe à maior parte da população analfabeta, sem recursos e castigada pela estiagem (PDTSP, 2010).

Assim, na configuração histórico-geográfica do Território Sertão Produtivo, garantir políticas públicas para os povos trabalhadores rurais torna-se uma tarefa extremamente difícil, o que compõe o cenário de fortalecimento da migração dos povos sertanejos do campo para os centros urbanos da região e, principalmente, para o centro-sul do Brasil. Ao comparar o número de habitantes do espaço rural de 2000 a 2010, observa-se que a maioria dos municípios diminuiu a população rural. No território como um todo, de 2000 para 2010, segundo os dados do Censo demográfico, houve uma diminuição de $7 \%$ da população rural e um aumento de $5,6 \%$ da população urbana.

Esse é o microcontexto que tem sido o campo de estudo da maior parte das pesquisas da linha, e suas características históricas, geoeconômicas e sociais são a base para uma análise dos caminhos das políticas públicas de Educação do Campo.

\section{Temas emergentes na política de Educação do Campo no Território de Identidade Sertão Produtivo}

\section{Políticas Públicas de Educação do Campo e Gestão}

De todas as produções da linha, identificamos vinte e dois trabalhos que discutem especificamente a Educação do Campo como política pública e a gestão escolar das instituições. Desses, dezessete abordam a política de educação do campo e trazem o debate sobre esta modalidade educacional de forma geral. Os demais textos articulam a luta dos movimentos sociais pela educação do campo e realizam a análise desta nos Planos Municipais de Educação e no quadro de oferta de vagas.

Os trabalhos que discutem a Educação do Campo, de modo geral, trazem o debate sobre a trajetória histórica da Educação do Campo, materialidade do conceito e sua legitimidade jurídica, os limites e possibilidades. Concebem a Educação do Campo como uma articulação necessária na luta pela transformação no campo, como caminho para uma formação humana e uma visibilidade social dos povos do campo. Em alguns desses trabalhos e no trabalho específico sobre movimentos sociais, destaca-se a articulação e a luta dos movimentos, organizações sociais e sindicais pela Educação do Campo. 
A Educação do Campo, fruto das lutas dos movimentos sociais organizados em coletivos no final da década de 1990 (MOLINA, 2010), hoje se constitui como uma das modalidades da educação básica do Brasil e tem garantida sua legitimidade jurídica nos Marcos Normativos da Educação do Campo, em destaque, nas Diretrizes Educacionais - Resolução nº 1 (BRASIL, 2002) e n 2 (BRASIL, 2008a) e no Decreto 7.352 (BRASIL, 2010).

Contudo, apesar de todo esse processo de institucionalização como forma de exigir do Estado o pagamento de uma dívida histórica no que tange ao acesso à educação escolar pelos povos do campo, as pesquisas evidenciam que, na realidade, os municípios do território ainda não têm conseguido efetivar os anseios desse movimento ocorrido a nível federal. Vilhena Júnior e Mourão (2012) destacam que, de modo geral, as ações para quem vive no campo nascem na esfera federal e, muitas vezes, não são executadas nos níveis estaduais e municipais, o que se torna ainda mais preocupante diante do atual governo federal no Brasil, que defende abertamente o agronegócio e o latifúndio ao desconsiderar os impactos ambientais e sociais do capital no meio rural. Os governos municipais e estaduais, e principalmente os movimentos sociais que não coadunam com tal perspectiva política, terão que se organizar ainda mais para garantir os direitos dos povos do campo.

Nesse cenário de antíteses, os trabalhos que analisam a realidade dos municípios do Sertão Produtivo evidenciam uma política de fechamento de escolas do campo e a não oferta da educação infantil na própria comunidade das crianças, exigência das Diretrizes (BRASIL, 2002, 2008a). Embora a maior parte dos Planos Municipais traga discussões de questões importantes relacionadas à Educação do Campo, como a formação dos professores, o currículo, o transporte escolar, não há um debate mais profundo da Educação do Campo como concepção de educação, e verifica-se uma certa invisibilidade sobre o fechamento das escolas. Ao mesmo tempo em que a Educação do Campo ganhou espaço nos documentos legais, dezenas de escolas do campo foram fechadas no Território, conforme abordaremos no próximo tópico.

Outro aspecto a ser destacado é que os Planos Municipais de Educação que foram construídos com efetiva participação dos grupos sociais organizados do campo são os que trazem uma análise mais crítica da realidade dos municípios e evidenciam o desacordo com a legislação nacional e com os anseios dos movimentos sociais.

Tais desafios de institucionalização da Educação do Campo nas escolas pode ser um dos elementos dificultadores das condições da gestão das escolas do campo. Nestas, a indicação política é predominante no cargo de direção; os/as diretores/as não residem no campo e o cargo tem alta rotatividade de profissionais. Acrescenta-se a isso o fato de que os conselhos escolares se reúnem apenas uma vez ao ano e há um número considerável de escolas sem 
conselho; e que os Projetos Políticos Pedagógicos das escolas são, na maioria dos casos, construídos com modelos já prontos, sem a participação da comunidade.

Segundo Nunes, Silva e Silva (2017), a perspectiva de gestão democrática presente nas diretrizes da Educação do Campo amplia os sujeitos participativos e inverte a lógica da gestão, uma vez que coloca escolas, comunidade e movimentos sociais juntos em prol de um desenvolvimento economicamente justo e ecologicamente sustentável para o campo. Para isso, as eleições diretas para diretores/as, um conselho gestor ativo e deliberativo, e um Projeto Político Pedagógico construído coletivamente com um diagnóstico local efetivo são primordiais.

As produções da linha que versam sobre esse tema demonstram como a Educação do Campo tem se fortalecido como movimento de luta pelo direito à educação no e do campo, seja na dimensão de luta coletiva, teórica ou no campo das políticas públicas. Contudo, garantir a efetivação da mesma na realidade dos municípios do Território Sertão Produtivo ainda é um desafio. É preciso garantir a existência das escolas no campo, a ampliação do debate sobre a concepção de Educação do Campo e uma gestão democrática com a participação da comunidade, dos movimentos sociais e sindicais da região.

\section{A negação da Educação do Campo como política: do fechamento à nucleação das escolas na cidade}

$\mathrm{Na}$ produção dos/as pesquisadores/as da linha, existem trinta trabalhos que abordam a política de nucleação e o fechamento das escolas do campo em alguns municípios do Território.

Desses, identificamos onze produções sobre nucleação: quatro (4) que tratam da política de nucleação; cinco (5) sobre os impactos do processo de fechamento das escolas, seja na aprendizagem ou na vida dos estudantes; um (1) sobre a prática dos/as professores/as e um (1) que trata da alteração do modelo multissérie para o seriado. Dez trabalhos tratam especificamente da nucleação extracampo, trazendo o olhar dos/as alunos/as do campo sobre a escola da cidade, as representações, o vivido e o desejado, as implicações no cotidiano e o processo de escolarização e a oferta de educação infantil para as crianças do campo na cidade.

Cinco produções têm como objeto da análise o fechamento das escolas do campo. Abordam o histórico de fechamento de escolas do campo, inclusive Escolas Família Agrícolas, as incertezas de continuidade de funcionamento de algumas instituições e os impactos na vida dos estudantes e suas famílias.

Os desgastes dos/as estudantes quanto ao deslocamento, os riscos a que são expostos/as no percurso casa-escola-casa e por estar na cidade são descritos por meio de metodologias que 
tomam as narrativas desses sujeitos como base empírica das análises. Do mesmo modo, problematizam-se as práticas escolares que não dialogam com as realidades e identidades dos povos do campo do território semiárido. A naturalização do fechamento das escolas é tão marcante que nos relatos das crianças do campo que estudam em escola nucleada na cidade a existência de uma escola no campo é algo longe de seu imaginário, reflexos da não política de educação nas suas comunidades.

A produção significativa sobre tal temática certamente tem relação com a prática corrente da nucleação intra e extracampo ${ }^{6}$ nos municípios do território. Com a justificativa de redução de custos, melhorar a qualidade estrutural das escolas do campo e acabar com a multissérie, muitos municípios vêm nucleando as escolas em comunidades rurais mais povoadas e, principalmente, nas cidades, o que consequentemente leva ao fechamento das escolas do campo.

Apesar da conquista dos marcos legais da Educação do Campo e da institucionalização da educação do campo como política pública pelo Decreto 7.352 (BRASIL, 2010), o direito à escolarização no meio rural ainda é um desafio latente no país e nos municípios do microcontexto aqui focalizado.

O Sertão Produtivo, dentre os territórios do estado da Bahia, foi considerado em 2014 como o quinto território em fechamento de escolas do campo. Ao analisarmos os dados sobre o número de estabelecimentos de ensino no campo do território, nos últimos dez anos (2009-2019), é possível identificar que, dos vinte municípios, dezoito diminuíram o número de escolas - em alguns casos, de forma drástica.

Gráfico 1 - Número de escolas no campo nos municípios do Território Sertão Produtivo (20092019)

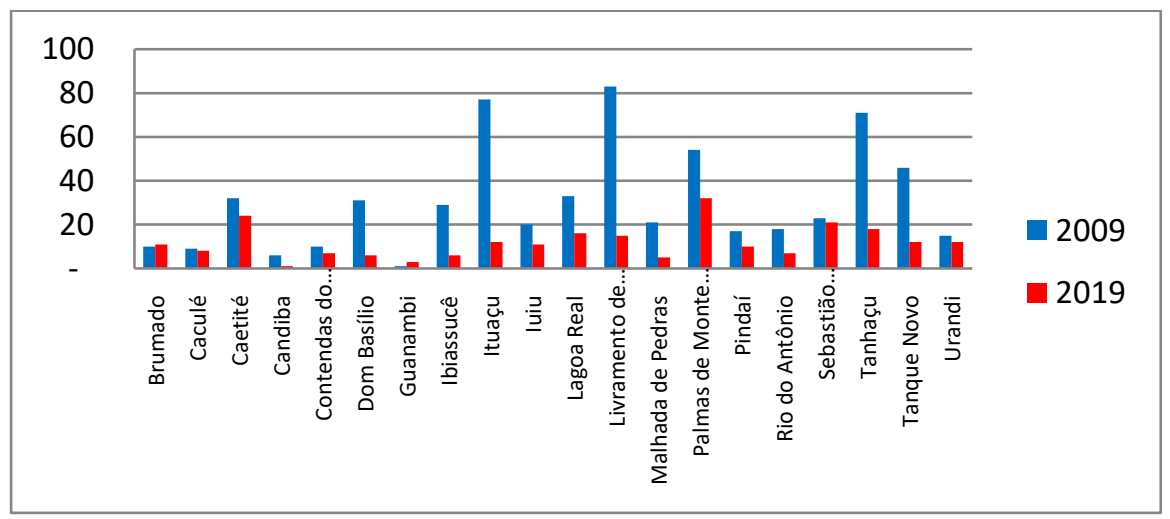

Fonte: Censo da Educação Básica 2009 - 2019 - INEP

${ }^{6}$ A Nucleação intracampo ocorre quando as escolas são nucleadas no próprio campo. Na nucleação extra campo as escolas são desativas no meio rural e os alunos remanejados para escolas na área urbana. 
No território como um todo, foram fechadas trezentos e sessenta e nove escolas, o que equivale a 60,9\%. Os municípios de Livramento de Nossa Senhora e Ituaçu, os com maior diminuição de escolas, fecharam juntos cento e trinta e três escolas do campo.

Cabe destacar que um dos municípios que aumentou o número de escolas, Guanambi, duas escolas a mais, o fez pela simples renomeação de escolas já existentes nos distritos como "escolas do campo". A maior parte das pesquisas que identificamos versa sobre esse município, evidenciando os impactos e a condição dos povos do campo estudando no meio urbano. Pesquisas crescentes para um número de escolas cada vez mais decrescente no campo.

Um outro aspecto evidenciado é que, embora a Resolução Complementar das Diretrizes da Educação do Campo (BRASIL, 2008a) tenha normatizado o processo de nucleação, recomendando que a mesma só pode acontecer intracampo a partir do estudo planejado do local, a exigência da oferta de educação infantil nas próprias comunidades e as considerações sobre o transporte escolar, os municípios vêm realizando a nucleação de forma desordenada, o que chega a ser denunciado como urbanização da educação.

Portanto, embora a Lei 12.960 (BRASIL, 2014), que alterou o artigo 28 da LDB 9.394/96 e acrescentou uma regulamentação sobre o fechamento das escolas rurais, afirme que esse processo só poderá acontecer mediante aprovação de órgão normativo, considerando a justificativa, a análise do diagnóstico do impacto da ação e a manifestação da comunidade escolar, os dados das pesquisas evidenciam que a luta pela efetivação do direto à educação escolar no campo ainda é um desafio posto nas políticas públicas educacionais. A consciência do direito tem avançado, conforme afirma Caldart (2002, p. 18): “[...] o povo do campo tem direito a educação no lugar onde vive; Do: o povo tem direito a uma educação pensada desde o seu lugar e com sua participação.”, agora é preciso criar um movimento de luta e resistência.

\section{A política de formação e trabalho de professores/as do campo no território Sertão Produtivo}

As pesquisas e projetos de extensão desenvolvidos ao longo de dez anos no território de identidade Sertão Produtivo, sistematizados em mais de vinte e uma publicações (dissertação, TCC, capítulos de livros, artigos em periódicos e anais de eventos), evidenciam que a formação e o trabalho de professores/as para uma escola do campo caracterizam-se como um não lugar. Isto é, um lugar negado, não ocupado, como foi pensado por Certau (1994).

Desde a formação anterior à exigência da LDBEN 9394/1996 de docentes licenciados/as para o trabalho na Educação Básica até as orientações dos marcos legais mais 
recentes, como as Diretrizes Operacionais para a Educação Básica nas escolas do campo (BRASIL 2002; 2008a), os cursos que formam professores/as, majoritariamente, pouco se ocuparam/ocupam das especificidades da docência nos contextos rurais.

Marques (2016) mostra que, nos cursos de licenciaturas, há uma invisibilidade da educação do campo, seja como conteúdo, disciplina ou práticas de estágio. No caso específico dos cursos de licenciatura da Uneb, presente por meio de três campi no Território de Identidade Sertão Produtivo e uma das instituições responsáveis pela formação de professores/as desse contexto, Marques et al (2016) verificaram que apenas o curso de licenciatura em Pedagogia (ofertado nos campi de Guanambi e Brumado) inclui em seu currículo uma disciplina denominada "Educação do campo" (60 horas). Nas demais licenciaturas, que formam professores/as para atuar nos anos finais do Ensino Fundamental e Ensino Médio, ofertadas no Campus da Uneb em Caetité, no Instituto Federal Baiano (IFBaiano - Campus Guanambi) ou em instituições privadas presentes na modalidade de Educação a Distância em todos os municípios do território, não existe nenhuma disciplina ou estágio em escolas do campo.

O que se observa nesse contexto, comum ao cenário nacional, é que o debate das especificidades para a docência em escolas no e do campo, não existe ou é incipiente. Somente professores/as que atuam na Educação Infantil, Anos Iniciais do Ensino Fundamental e na Educação de Jovens e Adultos (ciclos que correspondem aos anos iniciais do ensino fundamental), quando formados/as em Pedagogia pela Universidade do Estado da Bahia, aproximam-se do debate sobre as singularidades da docência com estudantes do campo e/ou em escolas no campo. Ainda assim, quando Marques et al. (2016) realizaram pesquisa com graduandos/as desse curso, as falas da maioria demonstram que a disciplina de 60 horas, por si só, não é suficiente para preparar os futuros docentes.

As únicas experiências de formação que se contrapõem à realidade apresentada se referem a políticas que se articulam a lutas de movimentos sociais pela Educação do Campo (Licenciatura em Pedagogia da Terra) e grupos de pesquisa que se colocam como protagonistas de projetos de formação continuada (curso de especialização Lato Sensu em Educação do Campo). Entretanto, ressalta-se que o curso Pedagogia da Terra, embora pesquisado por Marques (2010), foi desenvolvido no Campus XVII da Uneb e tem pouca incidência nas escolas do Território Sertão Produtivo. Já o curso de especialização Lato Sensu em Educação do Campo, ainda que seja caracterizado como de formação continuada, atendeu apenas a 21 professores/as que atuam em escolas do território, de um total, em 2019, de mil seiscentos e noventa e seis professores/as do campo (INEP, 2020). 
As produções que analisamos não indicam a existência de políticas e planos de formação de professores/as das escolas do campo, como Escola Ativa (BRASIL, 2008b); Escola da Terra (BRASIL, 2013) ${ }^{7}$ e o Programa de Apoio às Licenciaturas em Educação do Campo (Procampo) no Sertão Produtivo. Essas políticas, se são implementadas na região, têm pouca incidência ou ainda não foram objeto de estudo na linha de pesquisa em Educação do Campo, Educação de Jovens e Adultos e Movimentos Sociais do NEPE/Uneb.

O que os estudos realizados sobre o tema da formação e trabalho de professores/as nas escolas que atendem estudantes do campo demonstram é que as realidades rurais estão ausentes nos currículos da formação da maioria dos/as docentes que atuam no território cujos municípios têm maioria da população rural. Consequentemente, os saberes apontados por Silva e Pereira (2018) como necessários ao educador e à educadora do campo não se fazem presentes na atuação.

Nesse contexto, configuram-se políticas de formação e trabalho docente universalistas, conforme Arroyo (2007) discute. Para este autor, "nosso pensamento e nossa prática supõem que as políticas devam ser universalistas ou generalistas, válidas para todos, sem distinção" (ARROYO, 2007, p. 160). Assim sendo, as pesquisas mostram que, mesmo no Sertão Produtivo, onde há muitas crianças, jovens e adultos no campo ou que dele vivem, a formação dos/as professores/as e suas práticas se pautam no discurso de que "todos são iguais na escola". As diferenças e os diferentes, portanto, ficam de fora e uniformizam-se as pessoas.

\section{Escolhas políticas e pedagógicas: Implicações nas práticas e identidades das escolas do campo no Sertão Produtivo}

A análise de vinte e sete das produções da linha de pesquisa evidencia as práticas pedagógicas como escolhas políticas. Isto porque os textos avaliados versam sobre currículo e práticas docentes, tanto na Educação Infantil quanto nos anos iniciais e finais do Ensino Fundamental, e são marcados por escolhas de um projeto de escola-educação-sociedade. Essas escolhas apresentam-se na negação de um currículo que considere as especificidades do povo do campo, desde (e principalmente) a Educação Infantil. $\mathrm{O}$ estudo de Ferreira, Silva e Marques (2018) aponta que, apesar do esforço de algumas instituições escolares, os princípios da Educação do Campo ainda não se efetivam nas práticas pedagógicas, especialmente da Educação Infantil.

${ }^{7}$ Sobre o Programa Escola Ativa e Escola da Terra, especialmente no estado da Bahia, recomendamos a leitura de Taffarel e Santos Júnior (2016).

RIAEE - Revista Ibero-Americana de Estudos em Educação, Araraquara, v. 16, n. esp. 2, p. 1267-1285, maio 2021. e-ISSN: 1982-5587 
Neste sentido, observamos que nos vários estudos há uma lacuna em relação à legislação e à efetivação das ações. Baleeiro e Silva (2018) sinalizam para uma distância entre o legal e o real nas políticas educacionais que trabalham com os povos do campo. Já Pereira, Ribeiro e Trindade (2017, p. 38) afirmam que "Cada vez mais percebemos a implantação de uma política de desapropriação dos camponeses e o fortalecimento de uma educação baseada numa visão urbana, que não leva em conta as particularidades do campo".

Desse modo, podemos perceber que as escolhas políticas partem da negação a uma educação de qualidade, que proporcione aos/às estudantes do campo tomarem sua realidade como base para ampliação dos seus saberes. Essas escolhas refletem e, muitas vezes, definem a identidade da escola do campo. Ao analisar as pesquisas sobre identidade das escolas no território, percebemos que o processo de nucleação extracampo tem provocado o desenraizamento dos sujeitos campesinos (OLIVEIRA; REIS; COTRIM, 2011). Por outro lado, há escolas que resistem, mostrando-se integradas à comunidade, como aponta o estudo de Marques, Pereira e Pereira (2019). Essas escolas buscam nessa articulação com a comunidade pautar um currículo que dialoga com as especificidades dos/as estudantes.

Duarte, Morais e Silva (2017) sinalizam que, mesmo estando no campo, a escola pode não provocar sentimento de pertencimento na comunidade. Isso reafirma a importância de um currículo e um Projeto Político Pedagógico que escute as demandas locais, conforme preconizam as Diretrizes Operacionais e o Decreto 7.352 (BRASIL, 2010). As autoras apontam a necessidade de compreender esse sentimento de pertença dos alunos à escola no campo para promover uma educação de qualidade.

As reflexões e os resultados dos estudos contribuem para compreendermos que as políticas educacionais, concretizadas nas práticas pedagógicas, precisam levar em consideração a identidade das escolas, o contexto da comunidade e a identidade dos sujeitos - princípios basilares da Educação do Campo.

\section{Considerações finais}

O Território de Identidade Sertão Produtivo é marcado pela disputa de modelos de desenvolvimento antagônicos, uma forte presença histórica do latifúndio e grandes empreendimentos no âmbito da mineração e energia, em contraposição à realidade de municípios eminentemente rurais que sofrem com a negação de direitos, dentre eles o da educação. 
Compreender os modelos paradigmáticos em disputa local e no âmbito nacional torna mais precisa a análise dos reais desafios postos à efetivação da Educação do Campo como política e concepção de educação.

A análise das produções dos/as pesquisadores/as da Linha "Educação do Campo, Educação de Jovens e Adultos e Movimentos Sociais", do Núcleo de Estudo, Pesquisa e Extensão Educacional Paulo Freire (NEPE) do Departamento de Educação - DEDC XII - da Universidade do Estado da Bahia (Uneb), evidenciou que as pesquisas que dialogam com a política de educação básica do campo versam sobre as temáticas: Políticas públicas e a gestão; a política como negação de direitos, já que há um número considerável de produções sobre fechamento e nucleação das escolas do campo; a formação e a atuação de professores/as e as práticas pedagógicas. Identificamos ainda outros temas emergentes nas pesquisas, a exemplo daqueles que centralizam o protagonismo das mulheres, das juventudes e movimentos sociais enquanto demandantes de políticas públicas, mas que, para o escopo deste texto, optamos por não nos debruçar.

Em relação ao objetivo proposto - apresentar e analisar as políticas de Educação do Campo no microcontexto do Território de Identidade Sertão Produtivo na Bahia/Brasil - os resultados evidenciam as contradições da política pública para a Educação do Campo: uma crescente visibilização dessa modalidade educacional e seus/suas protagonistas; a inserção dessa pauta nos marcos legais e nas políticas municipais, ao mesmo tempo que ocorre o fechamento e a nucleação extracampo das escolas; políticas de formação e trabalho docente universalistas, bem como práticas pedagógicas que, enquanto escolhas políticas, negam a identidade e cultura dos povos do campo.

Tal cenário reforça a relevância das pesquisas desenvolvidas pela linha como forma de denúncia, registro histórico e como indicadoras de caminhos propositivos de ações no campo das políticas públicas educacionais locais. São dados científicos que evidenciam a necessidade de políticas públicas emancipatórias em contraposição às políticas públicas que têm mantido os povos do campo subordinados à lógica capitalista.

\section{REFERÊNCIAS}

ARROYO, M. G. Políticas de formação de educadores do campo. Cad. Cedes, Campinas, v. 27, n. 72, p. 157-176, maio/ago. 2007.

BALEEIRO, I. M.; SILVA, P. T. Panorama da Educação Infantil no Campo: entre o real e o legal. 2018. Monografia (Trabalho de Conclusão da Pós-Graduação Lato Sensu em Educação do Campo) - Universidade do Estado da Bahia, Guanambi, 2018. 
BRASIL. Conselho Nacional de Educação. Câmara de Educação Básica. Resolução CNE/CEB n. 01, de 03 de abril de 2002. Institui Diretrizes Operacionais para a Educação Básica nas Escolas do Campo. Diário Oficial da União, Brasília, 09 abr. 2002.

BRASIL. Conselho Nacional de Educação. Câmara de Educação Básica. Resolução CNE/CEB n. 02, de 28 de abril de 2008. Estabelece diretrizes complementares, normas e princípios para o desenvolvimento de políticas públicas de atendimento da Educação Básica do Campo. Diário Oficial da União, Brasília, 29 abr. 2008a.

BRASIL. Decreto n. 7.352, 04/11/2010. Política de Educação do Campo e o Programa Nacional de Educação e Reforma Agrária - PRONERA. Brasília, DF: Casa Civil, 2010.

BRASIL. Secretaria de Educação Continuada, Alfabetização e Diversidade. Ministério da Educação. Escola Ativa: projeto base. Brasília, DF: SECAD/MEC, 2008b.

BRASIL. Secretaria de Educação Continuada, Alfabetização e Diversidade e Inclusão. Ministério da Educação. Escola da Terra. Brasília, DF: SECAD/MEC, 03 out. 2013.

BRASIL. Lei n. 12.960, de 27 de março de 2014. Altera a Lei no 9.394 , de 20 de dezembro de 1996, que estabelece as diretrizes e bases da educação nacional, para fazer constar a exigência de manifestação de órgão normativo do sistema de ensino para o fechamento de escolas do campo, indígenas e quilombolas. Brasília, DF, 28 mar. 2014. Disponível em:

http://www.planalto.gov.br/ccivil 03/ ato2011-

2014/2014/lei/112960.htm\#: :text=LEI\%20N\%C2\%BA\%2012.960\%2C\%20DE\%2027,do\%20ca mpo\%2C\%20ind\%C3\%ADgenas\%20e\%20quilombolas. Acesso: 10 jun. 2020.

CALDART, R. S. Por uma educação do campo: traços de uma identidade em construção. In: ARROYO, M. G.; CALDART, R. S.; MOLINA, M. C. Por uma educação básica no campo: Identidade e políticas públicas. Brasília, 2002. v. 4

DUARTE, E. C. S.; MORAIS, E. S.; SILVA, P. T. Olhares dos alunos sobre a escola no campo do município de Urandi. In: SEMINÁRIO INTERNACIONAL, 1.; SEMINÁRIO

NACIONAL DE ESTUDOS, 4., 2017, São Carlos. Anais [...]. São Carlos, SP: UFSCAR, 2017.

FERNANDES, B. M. Construindo um estilo de pensamento na questão agrária: o debate paradigmático e o conhecimento demográfico. Tese (Livre-docência) - Universidade Estadual Paulista, Presidente Prudente, 2013.

FERNANDES, B. M. Políticas públicas, questão agrária e desenvolvimento territorial rural no Brasil. In: GRISA, C.; SCHNEIDER, S. Políticas públicas de desenvolvimento rural no Brasil. Porto Alegre: Editora da UFRGS, 2015. 624 p.

FERREIRA, A. T.; SILVA, P. T.; MARQUES, T. G. Educação Infantil no/do campo no município de Guanambi-BA: olhares sobre a oferta e o trabalho pedagógico. In: TRINDADE, D. R. et al. Sujeitos do campo em movimento: direitos, resistências e práticas formativas. Curitiba: CRV, 2018.

FRIGOTTO, G. Projeto societário contra-hegemônico e educação do campo: desafios de conteúdo, método e forma. In: MUNARIM, A. et al. (Org.). Educação do campo: reflexões e perspectivas. Florianópolis: Insular, 2010. p. 19-46. 
IBGE. Instituto Brasileiro de Geografia e Estatística. Censo demográfico 2000 e 2010. Disponível em: www.ibge.gov.br. Acesso em: maio. 2020.

INEP. Censo da Educação Básica 2009-2019. Disponível em: http://inep.gov.br/sinopsesestatisticas-da-educacao-basica. Acesso em: out. 2020.

MARQUES, T. G. Pedagogia da Terra: significados da formação para educadores e educadoras do campo. 2010. Dissertação (Mestrado) - Universidade Federal de Minas Gerais, Belo Horizonte, 2010.

MARQUES, T. G.; PEREIRA, E. S.; PEREIRA, R. Escola Municipal Colônia Agrícola de Ceraíma: história e significados para a comunidade. Revista ComCiência, v. 5, p. 1-10, 2019. Disponível em: http://www.revistacomciencia.com/arquivos/30.pdf. Acesso em 10 nov. 2020.

MARQUES, T. G. Os cursos de licenciatura e a formação para a docência em escolas no/do campo. Revista Cocar (Online), v. único, p. 76-97, 2016. Disponível em:

https://periodicos.uepa.br/index.php/cocar/article/view/1700. Acesso em: 10 dez 2020.

MARQUES, T. G. et al. O curso de Pedagogia e a formação de professores para a educação do/no campo: uma análise a partir das falas dos estudantes. In: SEMINARIO INTERNACIONAL DE LA RED ESTRADO, 6., 2016, Cidade do México. Anais [...]. Cidade do México, México: Universidad Pedagógica Nacional (UPN), 2016.

MÉSZÁROS, I. Para além do capital: rumo a uma teoria da transição. São Paulo: Boitempo, 2011.

MOLINA, M. C. Reflexões sobre o significado do protagonismo dos movimentos sociais na construção de políticas públicas de educação do campo. In: MOLINA, M. C. Educação do Campo e Pesquisa II: questões para reflexão. Brasília: MDA/MEC, 2010. p. 137-149.

NUNES, E. J. F. SILVA, P. T. SILVA, N.C. A educação do campo: perspectivas para um novo modelo de gestão escolar. In: SALES, M.V. S. (Org). Educação e contemporaneidade: perspectivas, interfaces e práticas formativas. Curitiba: CRV, 2017. v. 3.

OLIVEIRA, A.; REIS, C. M. D.; COTRIM, V. Da comunidade rural à escola da cidade: olhares dos sujeitos desses espaços. 2011. Monografia (Trabalho de Conclusão do Curso de Pedagogia) - Departamento de Educação Campus XII, Universidade do Estado da Bahia, 2011.

OLIVEIRA, D. A. Política educacional. In: OLIVEIRA, D. A.; DUARTE, A. M. C.; VIEIRA, L. M. F. Dicionário: trabalho, profissão e condição docente. Belo Horizonte: UFMG/Faculdade de Educação, 2010.

PEREIRA, L. S.; RIBEIRO, M. S.; TRINDADE, D. R. Educação do/no campo: um olhar sobre a prática do professor de educação física no município de Pindaí-BA. In: TRINDADE, D. R. et al. Práticas educativas, currículo e formação: múltiplos olhares. Fortaleza, CE: RDS, 2017.

PTDSP. Plano Territorial de Desenvolvimento Rural Sustentável do Sertão Produtivo. 1. ed. Bahia, dez. 2010. 
RIBEIRO, M. Movimento camponês, trabalho e educação: liberdade, autonomia, emancipação: princípios/fins da formação humana. São Paulo: Expressão Popular, 2010.

SANTOS, A. R.; BARBOSA, L. P.; ROSSET, P. M. Apresentação do Dossiê Temático. Práxis Educacional, Vitória da Conquista, v. 13, n. 26, 2018. Disponível em:

https://periodicos2.uesb.br/index.php/praxis/article/view/2818. Acesso em: 14 dez. 2020.

SILVA, P. T. O olhar da escola sobre a juventude do campo na comunidade de Mutãs Bahia: linhas que se cruzam, tessituras a se fazer. Programa de Pós-Graduação em Educação da Universidade Federal do Recôncavo da Bahia. 2015. 121 p. [Relatório Técnico]

SILVA, P. T.; LIMA, P. A.; BEBÉ, F. V. Desafios da agricultura familiar no Brasil e no Território Sertão Produtivo-BA. Entrelaçando: Revista Eletrônica de Culturas e Educação, ano v, n. 10, p. 37-51, 2016.

SILVA, P. T.; PEREIRA, E. S. Autonomia e Emancipação: saberes necessários ao educador e a educadora do campo. In: (Auto)nomia: atuação do educador em diferentes espaços. 1. ed. Curitiba: CRV, 2018. v. 1, p. 119-127.

VILHENA JÚNIOR, W. M.; MOURÃO, A. R. B. Políticas públicas e os movimentos sociais por uma Educação do Campo. In: GHEDIN, E. (Org.). Educação do campo: epistemologia e prática. 1. ed. São Paulo: Cortez, 2012.

\section{Como referenciar este artigo}

MARQUES, T. G.; PEREIRA, E. S.; SILVA, P. T. Políticas de educação do campo no território de identidade sertão produtivo na Bahia-Brasil: apontamentos de pesquisa. Revista Ibero-Americana de Estudos em Educação, v. 16, n. esp. 2, p. 1267-1285, maio 2021. eISSN: 1982-5587. DOI: https://doi.org/10.21723/riaee.v16iesp2.15125

Submissão em: $15 / 12 / 2020$

Revisões requeridas em: 28/01/2021

Aprovado em: 03/03/2021

Publicado em: 01/05/2021 